\title{
Extraction of Carotenoids and Fatty Acids from Microalgae Using Supercritical Technology ${ }^{*}$
}

\author{
Lourdes Casas Cardoso ${ }^{1 \#}$, Casimiro Mantell Serrano ${ }^{1}$, Miguel Rodríguez Rodríguez $^{1}$, \\ Enrique J. Martínez de la Ossa ${ }^{1}$, Luis M. Lubián ${ }^{2}$ \\ ${ }^{1}$ Department of Chemical Engineering and Food Technology, Faculty of Science, University of Cadiz, \\ International Agri-Food Campus of Excellence, Cadiz, Spain \\ ${ }^{2}$ Institute for Marine Science of Andalucia (CSIC), Cadiz, Spain \\ Email: "lourdes.casas@uca.es
}

Received September 11, 2012; revised October 18, 2012; accepted October 28, 2012

\begin{abstract}
The work described here is based on a comparative study of carotenoids and fatty acids extracted from Synechococcus sp. with 1) pure supercritical $\left.\mathrm{CO}_{2} ; 2\right) \mathrm{CO}_{2}$ with $5 \%$ (v/v) ethanol as cosolvent; and 3) ultrasound-assisted extraction using $\mathrm{N}, \mathrm{N}$-dimethylformamide (DMF). The effects of extraction conditions on supercritical $\mathrm{CO}_{2}$ extraction with and within cosolvent were analyzed at different temperatures $\left(40^{\circ} \mathrm{C}, 50^{\circ} \mathrm{C}\right.$ and $\left.60^{\circ} \mathrm{C}\right)$ and pressures $(200,300$ and 400 bars). SFE with $\mathrm{CO}_{2}$ proved to be the most selective method for the extraction of $\beta$-carotene, but under these conditions the contents of zeaxanthin and fatty acids were only comparable to or lower than those obtained with techniques that use SFE cosolvent. The SFE technique with $\mathrm{CO}_{2}$ and ethanol simultaneously extracted $\beta$-carotene and zeaxanthin and not only increased the concentrations of fatty acids obtained, but also helped to remove fatty acids (palmitoleic and linolenic acid) that were not obtained with pure $\mathrm{CO}_{2}$. Comparison of the supercritical technology with the ultrasound-assisted extraction (UAE) shows that the former technique is the most appropriate due to the fact that ethanol is generally regarded as a safe solvent in comparison to DMF.
\end{abstract}

Keywords: Carotenoids; Fatty Acids; Synechococcus sp.; Supercritical Technology; Ultrasound-Assisted Extraction

\section{Introduction}

In recent decades, there has been growing interest in the identification and characterization of high added value extracts from natural sources that are capable of providing additional benefits to human health. Such compounds include antioxidants, anti-inflammatory compounds and antihypertensive agents, among others.

In this respect, marine microalgae offer great potential as a source for the extraction of substances with desirable properties and these compounds are receiving attention in many industries, including the food, pharmaceutical and cosmetic industries [1]. These products are intended for direct human consumption and the mode of extraction is of paramount importance in terms of the technology applied. Furthermore, microalgae could provide the raw material to produce renewable fuels such as biodiesel, methane, hydrogen and ethanol. These biofuels are sulphur-free and perform the same functions as diesel oil while having the added benefit of reduced particulate, $\mathrm{CO}$ and hydrocarbon emissions.

\footnotetext{
*Extraction of active compounds from Synechococcus sp.

${ }^{\#}$ Corresponding author.
}

Supercritical fluid technology provides interesting alternatives for the extraction of substances from microalgae as these are efficient and selective methods. The application of this extraction technique with supercritical carbon dioxide has been widely studied in recent years due to the clear advantages of carbon dioxide as solvent - advantages that include low toxicity, low cost and ease of separation of the extracted product.

Numerous studies have been undertaken on the supercritical fluid extraction of carotenoids from different microalgae: Nannochloropsis gaditana [2], Synechococcus sp. [3-5], Dunaliella salina [6], Chlorella vulgaris [7,8], Scenedesmus almeriensis [9] and Nannochloropsis oculata [10]. In this respect it is worth highlighting the study carried out by Montero et al. [3] on Synechococcus sp. as this is the only study in which the main carotenoids obtained in the extracts were identified. However, in that study extractions were only carried out with pure $\mathrm{CO}_{2}$ and the effects of cosolvents were not investigated.

The extraction of fatty acids from different microalgae has also been studied and these include Arthrospira (Spirulina) [11], Chlorococcum sp. [12], Crypthecodinium cohnii [13] and Schizochytrium limacinum [14]. 
However, in these cases the compositions of the fatty acids for the microalga Synechococcus sp. were not reported.

The work described here focused on determining the concentration and composition of carotenoids and fatty acids obtained by supercritical fluid extraction of Synechococcus sp. Methanol is very efficient in removing large quantities of compounds in extraction processes but it is dangerous to humans and, as a result, ethanol was used as the eluent [15]. Furthermore, the influence of pressure and temperature on the yield of the supercritical extraction process was analysed and the results were compared to those obtained in the ultrasound-assisted extraction with DMF.

\section{Materials and Methods}

\subsection{Materials and Reagents}

Synechococcus sp. strain 01/0202 was obtained from the Marine Microalgae Culture Collection of the Institute for Marine Science of Andalucia (CSIC, Spain). Cells were grown in a $2 \mathrm{~L}$ bench-top photo-bioreactor (model Biostat-B, B Braun Biotech International $\mathrm{GmbH}$ ) during 4 days, in natural seawater filtered through a $1.0 \mu \mathrm{m}$ filter, sterilized in an autoclave $\left(120^{\circ} \mathrm{C}, 1 \mathrm{~kg}\right.$ pressure, $\left.15 \mathrm{~min}\right)$. Cultivation conditions were as follows: irradiance of 400 $\mu \mathrm{mol} \cdot$ quanta $\cdot \mathrm{m}^{-2} \cdot \mathrm{s}^{-1}$ and a temperature of $30^{\circ} \mathrm{C} . \mathrm{CO}_{2}$ (99.995\%), air, $\mathrm{H}_{2}$ and $\mathrm{He}$ were supplied by Abello Linde. $\beta$-Carotene, zeaxanthin and methyl ester standards were obtained from Sigma-Aldrich and the other reagents $(N$, $\mathrm{N}$-dimethylformamide (DMF), ethanol, methanol, acetonitrile (HPLC gradient grade) were supplied by Panreac.

\subsection{Extraction at High Pressure}

The extractions were carried out in an Isco extractor (Nebraska, USA, model SFX220). The equipment consisted of one extractor with a maximum capacity of 10 $\mathrm{mL}$ and $2 \mu \mathrm{m}$ filters at the inlet and outlet to avoid haulage of the sample. The extractor was also fitted with a thermostatic system that allowed the extraction to be carried out at a constant temperature. The solvent was introduced by syringe pumps (Isco, Nebraska, USA, model 260D and 100DX), which allowed a constant pressure to be achieved. The samples exited the vessel through a micrometric valve, which was thermo-stated to avoid obstructions at the exit due to solidification of $\mathrm{CO}_{2}$. The automatic control of the equipment made it possible for the pumps to work with different programmes. A cosolvent programme was used to enable a constant percentage flow-rate to be applied from a combination of the two pumps. The flow-rate was automatically measured by the programme based on the movement of the piston inside the syringe pump.
The extraction cartridge was loaded with approximately $4.6 \mathrm{~g}$ of sample, which had previously been homogenized to maintain a constant apparent density in all experiments. The cartridge was then introduced into the extractor and this was allowed to reach the desired operating temperature. The pumps were loaded with carbon dioxide and ethanol (HPLC grade) until the operating pressure was reached. The automatic decompression valves of the extractor were then closed. The valves connecting the pumps were opened in order to open the extractor. The extractor was then pressurized with $\mathrm{CO}_{2}$ and ethanol. When a balanced state was attained, the micrometric valve was opened until a constant flow of 0.8 $\mathrm{g} / \mathrm{min}$ was achieved.

A relatively long extraction time $(3 \mathrm{~h})$ was used in order to achieve complete extraction of the substances in question. The extracts were collected in glass tubes containing ethanol and were stored at $4^{\circ} \mathrm{C}$ with the exclusion of light.

Conditions of pressure were 200, 300 and 400 bar and the temperatures were $40^{\circ} \mathrm{C}, 50^{\circ} \mathrm{C}$ and $60^{\circ} \mathrm{C}$. Experiments were also carried out with pure $\mathrm{CO}_{2}$ and with $\mathrm{CO}_{2}$ containing $5 \%$ volume of ethanol as cosolvent, since this is the most commonly used system in the supercritical $\mathrm{CO}_{2}$ extraction of natural products. The results shown are averages of these two independent experiments and a reproducibility of approximately $6.3 \% \mathrm{cv}$ (coefficient of variation) was obtained.

The extraction yield was calculated according to the following equation:

$$
\%=W e / W i
$$

where \% is extraction yield, $W e$ is extract weight and $W i$ is initial weight expressed in grams.

\subsection{Ultrasound-Assisted Extraction}

DMF was selected as the solvent for ultrasound-assisted extraction (UAE) of pigments and fatty acids. The selection of this solvent is justified by the bibliography [6]. A sample of $0.105 \mathrm{~g}$ of lyophilized microalgae was suspended in $5 \mathrm{~mL}$ of the solvent. The suspension was sonicated for 3 minutes in an ultrasound apparatus from Selecta (Spain) and stored for $24 \mathrm{~h}$ at $4^{\circ} \mathrm{C}$. After this time, the extract was separated from the pellet and recovered by centrifugation, immediately filtered through a 0.22 $\mu \mathrm{m}$ filter, and finally stored at $4^{\circ} \mathrm{C}$ in the absence of light until analysis was carried out. The extraction process was repeated until the liquid extract did not have any coloration (approximately 6 extraction cycles).

\subsection{High-Performance Liquid Chromatography}

Pigments were analysed by HPLC using an Agilent Technologies Series 1100 chromatograph with a UV-vis 
detector and an automatic injector. Reversed phase C-18 columns packed with Hypersil ODS $(250 \mathrm{~mm} \times 4.6 \mathrm{~mm}$ i.d., $5 \mu \mathrm{m}$ particle size) were used. A mixture of acetone/methanol $(1: 1 \mathrm{v} / \mathrm{v})$ was used as solvent and the elution flow-rate was $1.5 \mathrm{~mL} / \mathrm{min}$. The detection wavelength was $450 \mathrm{~nm}$.

The major components ( $\beta$-carotene and zeaxanthin) were identified by comparison of their retention times with those of the commercial standards. Signals were recorded by Agilent chromatography software to show peak areas. Standard curves (pigment concentration versus peak area) were developed for zeaxanthin and $\beta$-carotene and the results are as follows:

\begin{tabular}{llll}
\hline$\beta$-carotene & $\mathrm{A}=-42.96+27.77 \mathrm{C}$ & $\mathrm{R}^{2}=0.9969$ \\
zeaxanthin & $\mathrm{A}=43.98+101.61 \mathrm{C}$ & $\mathrm{R}^{2}=0.9987$
\end{tabular}

where $\mathrm{A}$ is area, expressed as $\mathrm{mAu}$, and $\mathrm{C}$ is pigment concentration, expressed as $\mu \mathrm{g} / \mathrm{mL}$.

The experiments for each extraction were carried out in triplicate in order to evaluate the variability of the measurements. The results are shown as the average of all the independent analyses and the reproducibility was approximately $5.2 \% \mathrm{cv}$ (coefficient of variation).

\subsection{Gas Chromatography}

The fatty acid (FA) constituents were analyzed by gas chromatography (GC) (Agilent Technologies model 6890 $\mathrm{N})$ with a flame ionization detector and a capillary column (model SupraWAX-280, $30 \mathrm{~m}$ length $\times 0.25 \mathrm{~mm}$ internal diameter $\times 0.25 \mu \mathrm{m}$ thickness).

A $1 \mathrm{~mL}$ aliquot of the test sample was thoroughly mixed by dissolving $0.13 \mathrm{~g}$ of sample in $5.0 \mathrm{~mL}$ of n-hexane and $1.0 \mathrm{~mL}$ of $0.2 \mathrm{~N}$ hydrochloric acid in methanol was added to prepare fatty acid methyl esters (FAMEs). The methanolysis reaction was carried out using a heating block for a period of $4 \mathrm{~h}$. The extraction of FAMEs from the resulting mixture was carried out by adding $2 \mathrm{~mL}$ of $\mathrm{n}$-hexane (twice). The mixture was then shaken vigorously for $30 \mathrm{~s}$ and stored for $5 \mathrm{~min}$ so that it formed a bilayer. The clear upper layer containing the FAME $(10 \mu \mathrm{L})$ was injected into a gas chromatograph using an internal standard method [16].

The injector and detector temperatures were $200^{\circ} \mathrm{C}$ and $275^{\circ} \mathrm{C}$, respectively. The oven temperature was set at $90^{\circ} \mathrm{C}$ initially and was increased at a heating rate of $30^{\circ} \mathrm{C} / \mathrm{min}$ up to a temperature of $192^{\circ} \mathrm{C}$ and subsequently increased to $195^{\circ} \mathrm{C}$ at $2^{\circ} \mathrm{C} / \mathrm{min}$. The temperature was held for $5 \mathrm{~min}$ and finally increased at a heating rate of $2^{\circ} \mathrm{C} / \mathrm{min}$ up to the final temperature of $211^{\circ} \mathrm{C}$. The analysis was carried out in triplicate.

The FAME components were identified by compareson of their retention times with those of the commercial standards. Signals were recorded by Agilent chromatography software to obtain the peak areas. Heptadecanoic acid was used as the internal standard. The calibration curves were as follows:

\begin{tabular}{|c|c|c|c|}
\hline $\begin{array}{c}\text { Palmitic acid } \\
\text { C16:0 }\end{array}$ & $\mathrm{A}=-0.023+5.91 \mathrm{C}$ & $\mathrm{R}^{2}=0.9996$ & (4) \\
\hline $\begin{array}{l}\text { Palmitoleic } \\
\text { acid C16:1n-7 }\end{array}$ & $\mathrm{A}=0.029+5.02 \mathrm{C}$ & $\mathrm{R}^{2}=0.9943$ & (5) \\
\hline $\begin{array}{l}\text { Stearic acid } \\
\quad \text { C18:0 }\end{array}$ & $\mathrm{A}=-0.038+5.11 \mathrm{C}$ & $\mathrm{R}^{2}=0.9996$ & (6) \\
\hline $\begin{array}{l}\text { Oleic acid } \\
\text { C18:1 n-7 }\end{array}$ & $\mathrm{A}=0.024+5.18 \mathrm{C}$ & $\mathrm{R}^{2}=0.9936$ & (7) \\
\hline $\begin{array}{l}\text { Linoleic acid } \\
\text { C18:2 n-6 }\end{array}$ & $A=0.025+5.36 C$ & $\mathrm{R}^{2}=0.9995$ & (8) \\
\hline $\begin{array}{l}\text { Linolenic acid } \\
\text { C18:3 n-6 }\end{array}$ & $\mathrm{A}=0.029+5.09 \mathrm{C}$ & $\mathrm{R}^{2}=0.9994$ & (9) \\
\hline
\end{tabular}

where $\mathrm{A}$ is the area expressed in $\mathrm{Pa}$ and $\mathrm{C}$ is the FAME concentration expressed in $\mu \mathrm{g} / \mu \mathrm{L}$.

The experiments for each extraction were carried out in triplicate in order to evaluate the variability of the measurements. The results are shown as the average of all the independent analyses and the reproducibility was approximately $8.6 \% \mathrm{cv}$ (coefficient of variation).

\section{Results and Discussion}

\subsection{Extraction Yields}

The effect of temperature and pressure on the extraction yield with supercritical carbon dioxide from Synechococcus sp. is shown in Figure 1. It can be seen that a pressure of 200 bars gave the highest extraction yields at a temperature of $50^{\circ} \mathrm{C}$. This behaviour is similar to that observed with Nannochloropsis gaditana, Dunaliella salina and Chlorela vulgaris [2,6,17].

At this pressure (200 bars), the slight increase in the extraction yield observed on increasing the temperature from $40^{\circ} \mathrm{C}$ to $50^{\circ} \mathrm{C}$ is attributed to an increase in the vapour pressure of the solutes and the increase in the diffusivity of the $\mathrm{CO}_{2}$. On the other hand, when the temperature was increased from $50^{\circ} \mathrm{C}$ to $60^{\circ} \mathrm{C}$, the effect that prevailed was the decrease in the density of the solvent and this was not compensated by the increase in the diffusiveity and the vapour pressure of the solutes to be extracted.

At higher pressure (300 bars) an increase in the temperature from $40^{\circ} \mathrm{C}$ to $60^{\circ} \mathrm{C}$ proved beneficial to the extraction process because the effect that prevailed was the increase in the vapour pressure of the substances to be extracted. This increase in extraction yield was more marked at 400 bars than at 300 bars. At a pressure of 400 bars an increase in temperature from $40^{\circ} \mathrm{C}$ to either $50^{\circ} \mathrm{C}$ or $60^{\circ} \mathrm{C}$ provided a similar extraction yield. In this case there was compensation between the decrease in the su- 
percritical carbon dioxide density and the increase in vapour pressure of the compounds as the temperature increased.

A major drawback in the use of supercritical $\mathrm{CO}_{2}$ is its low polarity, which makes the extraction of polar solutes difficult. Nevertheless, this limitation may be overcome by adding to the supercritical $\mathrm{CO}_{2}$ small amounts of polar modifiers, such as methanol or ethanol, in order to increase the solvation power. It has been reported in various studies that ethanol is the most effective modifier in the extraction of $\beta$-carotene from vegetables [18] and this was therefore chosen as the cosolvent in this study.

The extraction yields obtained with supercritical $\mathrm{CO}_{2}$ and $5 \%(\mathrm{v} / \mathrm{v})$ ethanol as cosolvent at different temperatures and pressures are also shown in Figure 1. The addition of ethanol as a cosolvent led to an increase in yield in all experiments. Furthermore, since analytes with different polarities show better recovery levels in the supercritical $\mathrm{CO}_{2}$ fluid with added ethanol, the effect of the cosolvent is related not only to the change in polarity of the extraction fluid but also to its interaction with the matrix.

It can be seen from Figure 1 that, at a constant pressure, increases in the temperature favoured the extraction process in all case. For each temperature, an increase in
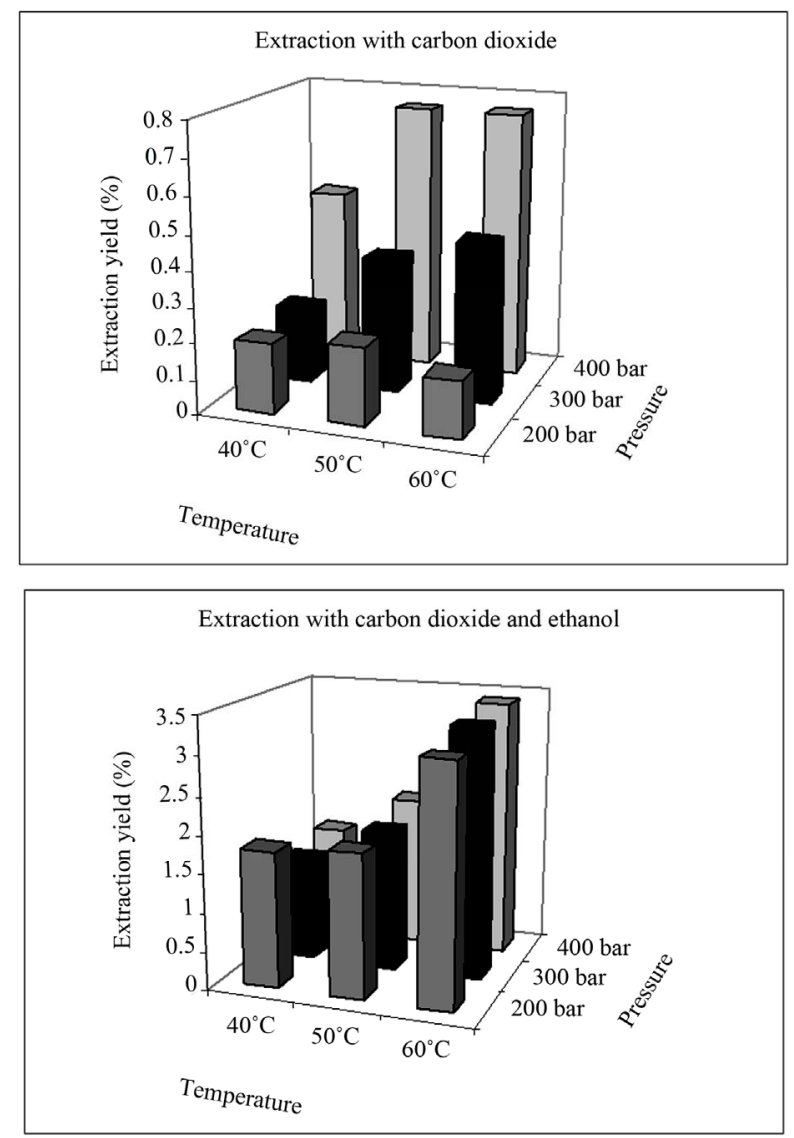

Figure 1. Extraction yields of samples. the operating pressure led to two opposing effects: an increase in the solvent power and a decrease in its diffusivity. At $40^{\circ} \mathrm{C}$ the maximum extraction yields were achieved at 200 bars and in this case the dominant effect was the solvent power. At high pressure, however, this effect was unable to counteract the decrease in the solvent diffusivity and a decrease in the extraction yield was observed.

At $50^{\circ} \mathrm{C}$ and $60^{\circ} \mathrm{C}$ increases in pressure led to increases in the density of the supercritical fluid and, as a result, its solvating power was enhanced. This led to a greater quantity of solutes being transferred to the supercritical solvent and the extraction process was favoured.

\subsection{Carotenoids}

The yields of $\beta$-carotene in the extracts obtained with pure supercritical $\mathrm{CO}_{2}$ and $\mathrm{CO}_{2}$ with $5 \%(\mathrm{v} / \mathrm{v})$ ethanol at different pressures and temperatures are represented in Figure 2. It can be seen that the $\beta$-carotene content depends strongly on the extraction conditions. $\beta$-Carotene was only partially removed with pure $\mathrm{CO}_{2}$ and its content
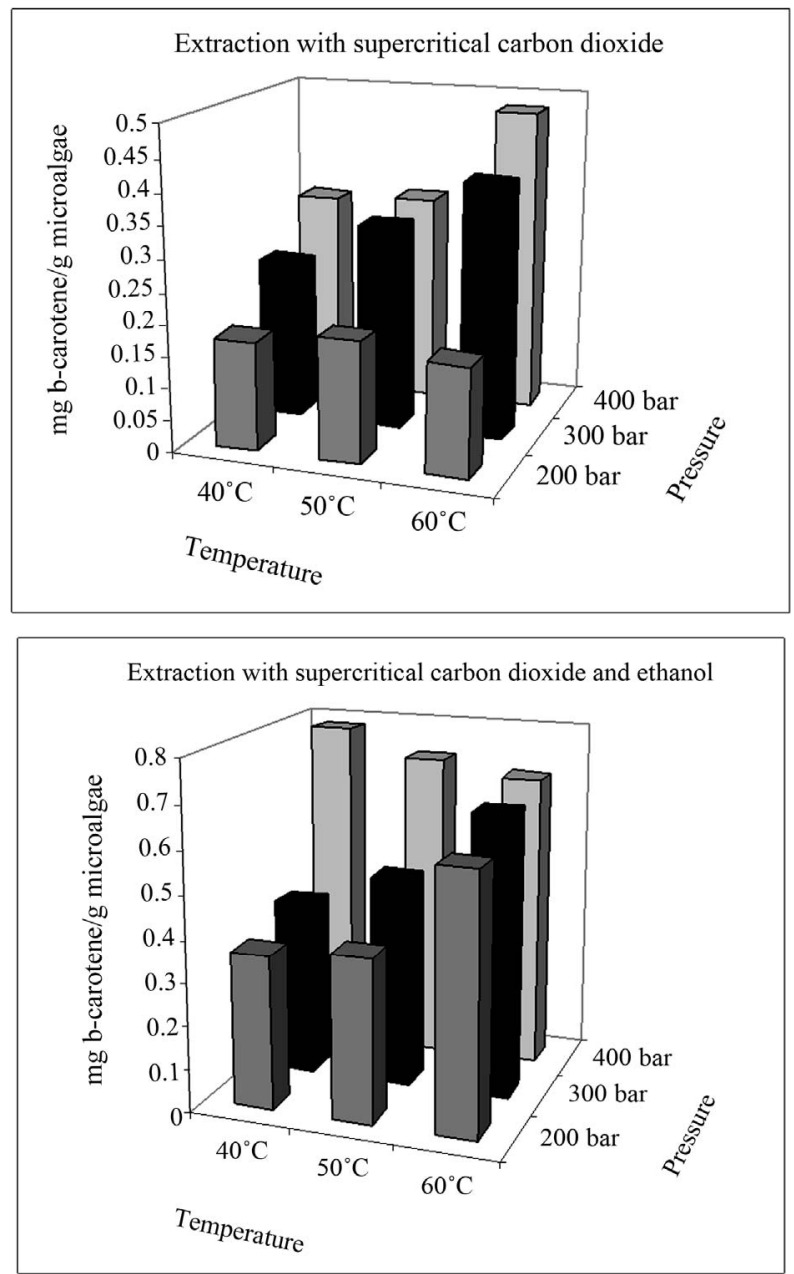

Figure 2. Extraction yields of $\beta$-carotene. 
in the extract did not exceed $0.48 \mathrm{mg} / \mathrm{g}$ microalgae (dried). Nevertheless, the use of $\mathrm{CO}_{2}$ with $5 \%(\mathrm{v} / \mathrm{v})$ ethanol as a cosolvent led to an improvement in the extraction of $\beta$-carotene, with concentrations higher than $0.70 \mathrm{mg} / \mathrm{g}$ microalgae (dried) achieved. The highest extraction yields were obtained at 400 bars and $40^{\circ} \mathrm{C}$ with $\mathrm{CO}_{2}+5 \%(\mathrm{v} / \mathrm{v})$ of ethanol as cosolvent.

Comparison of the results obtained with $\mathrm{CO}_{2}$ and those obtained in another study [3] shows that the best extraction yields were obtained in the current work, not only because the equipment used was an extractor with a capacity 20 times that in the aforementioned study but also because the strain and culture conditions were different, thus causing a change in the concentration and composition of the microalgae.

In this regard, it is worth noting that when optimizing the extraction process a very important factor is the selection of the cultivation method for the microalgae, since this affects both the composition and quantity of pigments. These considerations explain why only the zeaxanthin extraction yields obtained with $\mathrm{CO}_{2}$ and $5 \%$ $(\mathrm{v} / \mathrm{v})$ ethanol are shown in Figure 3, for the same pressure and temperature conditions, since the content of zeaxanthin in extracts obtained with supercritical $\mathrm{CO}_{2}$ alone is below the detection limit of the analytical technique. This result is due to the low solubility of zeaxanthin in $\mathrm{CO}_{2}$. The effect that pressure and temperature have on the extraction yield is different to the variation discussed in the case of $\beta$-carotene. In this case, an increase in the temperature always led to higher extraction yields. On the other hand, the highest extraction yields were obtained at lower pressures. The highest extraction yields of zeaxanthin were obtained at 200 bars and $60^{\circ} \mathrm{C}$ with $\mathrm{CO}_{2}+5 \%(\mathrm{v} / \mathrm{v})$ ethanol as cosolvent.

This type of microalga gave a significant amount of zeaxanthin in the extraction with supercritical $\mathrm{CO}_{2}$ at a pressure of 500 bars [3]. However, it should be noted that

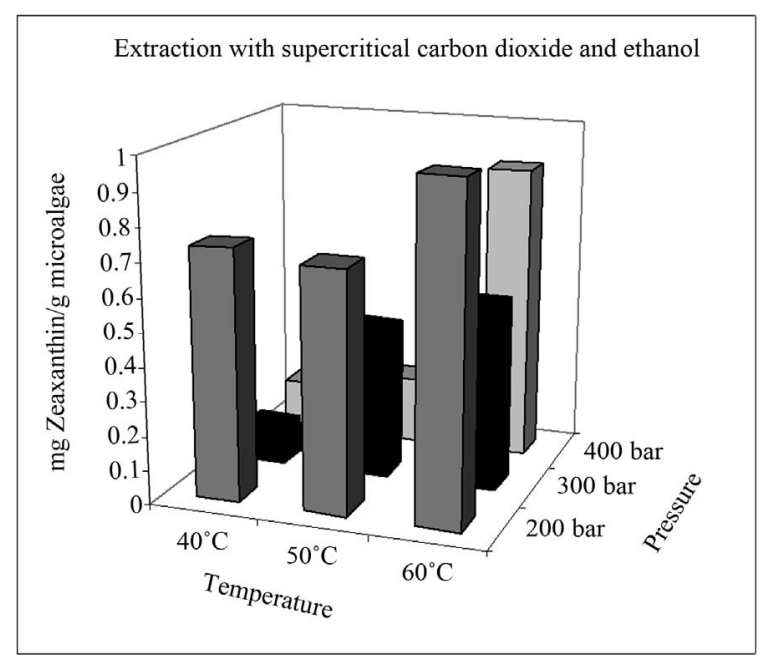

Figure 3. Extraction yields of zeaxanthin. both the original strain and culture conditions are also different. This again highlights the importance of controlling the cultivation conditions to obtain reproducible amounts of pigments.

The $\mathrm{CO}_{2}$ extraction of $\beta$-carotene did not give rise to an appreciable content of zeaxanthin. However, it must be borne in mind that the highest yield in the extraction of $\beta$-carotene was obtained on using $\mathrm{CO}_{2}$ and $5 \%$ ethanol as cosolvent, but under these conditions zeaxanthin was also extracted.

Although the zeaxanthin molecule is not considered to contain strong polar moieties, it is a large molecule and this inhibits its solubility in pure supercritical $\mathrm{CO}_{2}$ due to its low volatility [19]. As a result, it is necessary to use cosolvents such as ethanol or vegetable oils to increase the extraction yield.

The supercritical extraction process of total carotenoids from the microalga Synechococcus sp. has been reported in other studies [4,5]. It is worth noting, however, that higher extraction yields were obtained in the work described here. These differences can be attributed to the fact that the extractors used in the two studies differ in size. Nevertheless, although the starting strain and cultivar conditions are different for the data reported, the behaviour observed for the extraction yields on changing pressure and temperature conditions is the same.

\subsection{Fatty Acids}

The fatty acid compositions in the extracts obtained with $\mathrm{CO}_{2}$ and $\mathrm{CO}_{2}$ with $5 \%(\mathrm{v} / \mathrm{v})$ ethanol as cosolvent at different pressures and $60^{\circ} \mathrm{C}$ are shown in Table 1. The addition of ethanol as cosolvent not only increased the concentrations of fatty acids obtained, but also helped to remove fatty acids (palmitoleic and linolenic acid) that were not obtained with $\mathrm{CO}_{2}$ alone. These results are similar to those found by other researchers on using 250 bars and $50^{\circ} \mathrm{C}[11]$.

It can be seen from Figure 1 that an isothermal increase in pressure caused large variations in the total yields of extracts. However, this behaviour is not analogous to that of fatty acids. At the three pressures studied (200, 300 and 400 bars) the fatty acid content was similar between extractions when $\mathrm{CO}_{2}$ was used, and only in the case of palmitic acid were increases in content observed on increasing the pressure (Table 1). This behaviour was also observed when ethanol was added to $\mathrm{CO}_{2}$ as a cosolvent.

Palmitic acid (16:0) is a saturated fatty acid that was predominant in all tests and linoleic acid (C18:2) is a polyunsaturated fatty acid that also predominated, albeit to a much lesser extent than $\mathrm{C} 16: 0$. For this reason, the application of this approach in the production of biofuels would be inadvisable due to the high concentrations of saturated fatty acids [12]. 
Table 1. Composition in fatty acids (mg/g microalgae) of the extracts obtained with pure $\mathrm{CO}_{2}$ and $\mathrm{CO}_{2}+5 \%(\mathrm{v} / \mathrm{v})$ of ethanol at $60^{\circ} \mathrm{C}$.

\begin{tabular}{ccccccc}
\hline \multirow{2}{*}{ Fatty acids } & \multicolumn{3}{c}{$\mathrm{CO}_{2}$} & \multicolumn{3}{c}{$\mathrm{CO}_{2}$ and 5\% (v/v) ethanol } \\
\cline { 2 - 7 } & $200 \mathrm{bar}$ & $300 \mathrm{bar}$ & $400 \mathrm{bar}$ & $200 \mathrm{bar}$ & $300 \mathrm{bar}$ & $400 \mathrm{bar}$ \\
\hline Palmitic acid C16:0 & $1.66 \pm 0.1$ & $2.71 \pm 0.3$ & $3.47 \pm 0.4$ & $4.12 \pm 0.5$ & $5.19 \pm 0.5$ & $6.57 \pm 0.4$ \\
Palmitoleic acid C16:1 & - & - & - & $0.12 \pm 0.1$ & $0.14 \pm 0.1$ & $0.18 \pm 0.1$ \\
Stearic acid C18:0 & $0.44 \pm 0.3$ & $0.37 \pm 0.2$ & $0.46 \pm 0.3$ & $2.12 \pm 0.5$ & $2.14 \pm 0.4$ & $2.44 \pm 0.4$ \\
Oleic acid C18:1 & $0.04 \pm 0.01$ & $0.06 \pm 0.02$ & $0.05 \pm 0,01$ & $0.14 \pm 0.1$ & $0.14 \pm 0.1$ & $0.14 \pm 0.1$ \\
Linoleic acid C18:2 & $0.23 \pm 0.1$ & $0.26 \pm 0.1$ & $0.22 \pm 0.1$ & $2.93 \pm 0.6$ & $2.95 \pm 0.7$ & $3.21 \pm 0.8$ \\
Linolenic acid C18:3 & - & - & - & $0.09 \pm 0.08$ & $0.11 \pm 0.09$ & $0.10 \pm 0.09$ \\
\hline
\end{tabular}

$(-)$ : Not detectable.

Table 2. Comparison of the extraction yields obtained by SFE and UAE in carotenoids and fatty acids (mg/g extract).

\begin{tabular}{|c|c|c|c|c|}
\hline & $\mathrm{CO}_{2} 400$ bar & $\begin{array}{c}\mathrm{CO}_{2}+\text { ethanol } \\
200 \text { bar }\end{array}$ & $\begin{array}{c}\mathrm{CO}_{2}+\text { ethanol } \\
400 \text { bar }\end{array}$ & UAE-DMF \\
\hline$\beta$-carotene & $64.00 \pm 1.2$ & $19.35 \pm 0.9$ & $20.35 \pm 2.1$ & $42.53 \pm 2.3$ \\
\hline zeaxanthin & - & $31.61 \pm 1.3$ & $25.96 \pm 1.8$ & $10.09 \pm 1.5$ \\
\hline $\begin{array}{l}\text { Palmitic acid } \\
\text { C16:0 }\end{array}$ & $459.21 \pm 2.9$ & $132.33 \pm 2.6$ & $193.75 \pm 2.4$ & $59.38 \pm 1.8$ \\
\hline $\begin{array}{l}\text { Palmitoleic } \\
\text { acid C16:1 }\end{array}$ & - & $3.85 \pm 0.8$ & $5.30 \pm 0.7$ & $8.89 \pm 0.9$ \\
\hline $\begin{array}{c}\text { Stearic acid } \\
\text { C18:0 }\end{array}$ & $60.87 \pm 0.9$ & $68.09 \pm 0.9$ & $71.96 \pm 0.7$ & - \\
\hline $\begin{array}{l}\text { Oleic acid } \\
\text { C18:1 }\end{array}$ & $6.62 \pm 0.3$ & $4.50 \pm 0.3$ & $4.13 \pm 0.2$ & $6.47 \pm 0.5$ \\
\hline $\begin{array}{c}\text { Linoleic acid } \\
\text { C18:2 }\end{array}$ & $29.11 \pm 1.3$ & $94.11 \pm 1.5$ & $94.66 \pm 1.6$ & $2.11 \pm 0.5$ \\
\hline $\begin{array}{c}\text { Linolenic acid } \\
\text { C18:3 }\end{array}$ & - & $2.89 \pm 0.3$ & $2.95 \pm 0.5$ & $0.23 \pm 0.09$ \\
\hline
\end{tabular}

(-): Not detectable.

\subsection{Comparison between Methods}

When the extraction process was carried out by ultrasound using DMF as solvent, a significant increase in the extraction yield $(12.43 \%)$ was obtained; cf. $0.75 \%$ obtained with $\mathrm{CO}_{2}$ at $60^{\circ} \mathrm{C}, 400$ bars and $3.39 \%$ obtained with $\mathrm{CO}_{2}$ and $5 \%(\mathrm{v} / \mathrm{v})$ ethanol as co-solvent at 400 bars and $60^{\circ} \mathrm{C}$ (Figure 1).

The comparisons corresponding to the best results obtained by SFE and those obtained by UAE using DMF as solvent are shown in Table 2. SFE with $\mathrm{CO}_{2}$ proved to be the most selective method for the extraction of $\beta$-carotene, but under these conditions the contents of zeaxanthin and fatty acids were only comparable to or lower than those obtained with techniques that use SFE cosolvent. Only in the case of palmitic acid are the results better than for the other techniques used.

The SFE technique with $\mathrm{CO}_{2}$ and ethanol simultaneously extracted $\beta$-carotene and zeaxanthin. The extraction carried out at 200 bars and $60^{\circ} \mathrm{C}$ with $\mathrm{CO}_{2}$ and $5 \%$ ethanol led to the highest content of zeaxanthin. However, when an extract that is rich in fatty acids is required, it is advisable to increase the pressure to 400 bars (Table 1).

UAE gave rise to higher concentrations of $\beta$-carotene than SFE with co-solvent, although the recovery of zeaxanthin with ultrasound is low compared to SFE with co-solvent. It is important to note the high content of palmitoleic and oleic acids obtained with DMF in conjunction with ultrasound. Ethanol is a more acceptable solvent than the DMF used in the ultrasound-assisted extraction because it is less harmful to humans and the environment. However, it is worth noting that the supercritical $\mathrm{CO}_{2}$ extraction with ethanol is the most appropriate method for the simultaneous acquisition of all compounds studied.

\section{Conclusions}

Synechococcus sp. represents a natural source for the production of carotenoids, mainly $\beta$-carotene, that can be used in the food industry as additives with antioxidant and immune system enhancing properties. This microalga is also a source of zeaxanthin, which contributes to the protection of the human retinal from ultraviolet radiation from the sun.

The fatty acid compositions obtained provide evidence that these algae are rich in saturated fatty acids, which are frequently used in the manufacture of soaps, cosmetics, detergents, lubricants, protective coatings and chemical intermediates.

\section{REFERENCES}

[1] R. Harun, M. Singh, G. Forde and M. Danquah, "Bioprocess Engineering of Microalgae to Produce a Variety of Consumer Products," Renewable and Sustainable Energy, Vol. 14, No. 2, 2010, pp. 1037-1047. doi:10.1016/j.rser.2009.11.004

[2] M. D. Macías-Sánchez, C. Mantell, M. Rodríguez, E. Martínez de la Ossa, L. M. Lubián and O. Montero, "Super- 
critical Fluid Extraction of Carotenoids and Chlorophyll $a$ from Nannochloropsis gaditana," Journal of Food Engineering, Vol. 66, No. 2, 2005, pp. 245-251. doi:10.1016/i.jfoodeng.2004.03.021

[3] O. Montero, M. D. Macías-Sánchez, C. M. Lama, L. M. Lubián, C. Mantell, M. Rodríguez and E. Martínez de la Ossa, "Supercritical $\mathrm{CO}_{2}$ Extraction of $\beta$-Carotene from a Marine Strain of the Cyanobacterium Synechococcus Species," Journal of Agriculture and Food Chemistry, Vol. 53, No. 25, 2005, pp. 9701-9707. doi:10.1021/jf051283n

[4] M. D. Macías-Sánchez, C. Mantell, M. Rodríguez, E. Martínez de la Ossa, L. M. Lubián and O. Montero, "Extraction of Carotenoids and Chlorophyll from Microalgae with Supercritical Carbon Dioxide and Ethanol as Cosolvent," Journal of Separation Science, Vol. 31, No. 8, 2008, pp. 1352-1362. doi:10.1002/jssc.200700503

[5] M. D. Macías-Sánchez, C. Mantell, M. Rodríguez, E. Martínez de la Ossa, L. M. Lubián and O. Montero, "Supercritical Fluid Extraction of Carotenoids and Chlorophyll a from Synechococcus sp.," Journal of Supercritical Fluid, Vol. 39, No. 3, 2007, pp. 323-329. doi:10.1016/j.supflu.2006.03.008

[6] M. D. Macías-Sánchez, C. Mantell, M. Rodríguez, E. Martínez de la Ossa, L. M. Lubián and O. Montero, "Comparison of Supercritical Fluid and Ultrasound-Assisted Extraction of Carotenoids and Chlorophyll a from Dunaliella salina," Talanta, Vol. 77, No. 3, 2009, pp. 948952. doi:10.1016/j.talanta.2008.07.032

[7] R. L. Mendes, H. L. Fernandes, J. P. Coelho, E. C. Reis, J. M. S. Cabral, J. M. Novais and A. F. Palavra, "Supercritical $\mathrm{CO}_{2}$ Extraction of Carotenoids and Other Lipids from Chlorella Vulgaris," Food Chemistry, Vol. 53, No. 1, 1995, pp. 99-103. doi:10.1016/0308-8146(95)95794-7

[8] K. Kitada, S. Machmudah, M. Sasaki, M. Goto, Y. Nakashima, S. Kumamoto and T. Hasegawa, "Supercritical $\mathrm{CO}_{2}$ Extraction of Pigment Components with Pharmaceutical Importance from Chlorella Vulgaris," Journal of Chemical Technology and Biotechnology, Vol. 84, No. 5, 2009, pp. 657-661. doi:10.1002/jctb.2096

[9] M. D. Macías-Sánchez, J. M. Fernandez-Sevilla, F. G. Acién-Fernández, M. C. Cerón-García and E. MolinaGrima, "Supercritical Fluid Extraction of Carotenoids from Scenedesmus almeriensis," Food Chemistry, Vol. 123, No. 3, 2010, pp. 928-935.

doi:10.1016/i.foodchem.2010.04.076

[10] L. Bing-Chung, S. Chun-Ting, L. Fong-Ping, H. Siang-En, H. Shih-Lan, J. Ting-Ting and J. C. Chieh-Ming, "Supercritical Fluids Extraction and Anti-Solvent Purification of Carotenoids from Microalgae and Associated Bioactiv- ity," Journal of. Supercritical Fluid, Vol. 55, No. 1, 2010 , pp. 169-175. doi:10.1016/j.supflu.2010.07.002

[11] R. L. Mendes, A. D. Reis and A. F. Palavra, "Supercritical $\mathrm{CO}_{2}$ Extraction of $\gamma$-Linolenic Acid and Other Lipids from Arthrospira (Spirulina) Maxima: Comparison with Organic Solvent Extraction," Food Chemistry, Vol. 99, No. 1, 2006, pp. 57-63. doi:10.1016/i.foodchem.2005.07.019

[12] M. J. Ramos, C. M. Fernández, A. Casas, L. Rodríguez and A. Pérez, "Influence of Fatty Acid Composition of Raw Materials on Biodiesel Properties," Bioresource Technology, Vol. 100, No. 1, 2009, pp. 261-268. doi:10.1016/j.biortech.2008.06.039

[13] R. M. Couto, P. C. Simoes, A. Reis, T. L., Da Silva, H. V. Martins and Y. Sanchez-Vicente, "Supercritical Fluid Extraction of Lipids from the Heterotrophic Microalgae Crypthecodinium cohnii," Engineering in Life Science, Vol. 10, No. 2, 2010, pp. 158-164.

[14] S. Tang, C. Qin, H. Wang, S. Li and S. Tian, "Study on Supercritical Extraction of Lipids and Enrichment of DHA from Oil-Rich Microalgae," Journal of Supercritical Fluid, Vol. 57, No. 1, 2011, pp. 44-49.

doi:10.1016/j.supflu.2011.01.010

[15] M. Mukhopadhyay, "Extraction and Processing with Supercritical Fluids," Journal of Chemical Technology and Biotechnology, Vol. 84, No. 1, 2009, pp. 6-12. doi: $10.1002 /$ jctb. 2072

[16] A. Demirbas, "Progress and Recent Trends in Biodiesel Fuels," Energy Conversion and Management, Vol. 50, No. 1, 2009, pp. 14-34. doi:10.1016/j.enconman.2008.09.001

[17] R. L. Mendes, B. P. Nobre, M. T. Cardoso, A. P. Pereira and A. F. Palavra, "Supercritical Carbon Dioxide Extraction of Compounds with Pharmaceutical Importance from Microalgae," Inorganica Chemica Acta, Vol. 356, No. 3, 2003, pp. 328-334. doi:10.1016/S0020-1693(03)00363-3

[18] M. Careri, L. Flurlattini, A. Mangia, M. Musci, E. Anklam, A. Theobald and C. Von Holst, "Supercritical Fluid Extraction for Liquid Chromatographic Determination of Carotenoids in Spirulina Pacifica Algae: A Chemometric Approach," Journal of Chromatography A, Vol. 912, No. 1, 2001, pp. 61-71. doi:10.1016/S0021-9673(01)00545-3

[19] D. Dandge, J. Heller and K. Wilson, "Structure Solubility Correlations: Organic Compounds and Dense Carbon Dioxide Binary Systems," Industrial \& Engineering Chemistry Product Research and Development, Vol. 24, No. 1, 1985, pp. 162-166. doi:10.1021/i300017a030 